International Journal of Computer Science \& Engineering Survey (IJCSES) Vol.10, No.1, February 2019

\title{
REVIEW AND ANALYSIS ON TELECOMMUNICATION NETWORKS INFRASTRUCTURE IN THE NORTHWEST PROVINCE OF NigERIA FOR OPTIMISATION: PROBleMS AND SOLUTIONS
}

\author{
Sanusi Mohammed Bunu ${ }^{1}$, Murtala Muhammad ${ }^{2}$ and Hamid Abubakar Adamu ${ }^{3}$ \\ ${ }^{1}$ Department of Computer Science, Adamawa State Polytechnic, Yola, Adamawa State, \\ Nigeria \\ ${ }^{2}$ Computer Science Department, Adamawa State University Mubi, Adamawa State, \\ Nigeria \\ ${ }^{3}$ Department of Mathematics, Adamawa State University Mubi, Adamawa State, Nigeria
}

\begin{abstract}
Telecommunication network infrastructure determines the strength of a country for successful communication with other parts of the world. Due to the rapid increase of internet usage and mobile communication in every part of the world, specifically the third world countries, Nigeria is among the countries that is advancing in the used of telecommunication contraptions. The Nigerian Telecommunication Industries play a vital role in boosting the social and economic infrastructure of the country. This paper is aimed at investigating the Telecommunication Network infrastructure in the Northwestern part of Nigerian and propose some technologies that increase data bandwidth and internet penetration in the region. Problems and future solutions to the existing network infrastructure in the province were discussed and basic analysis is conducted to justify the importance of the study. Mobile market analysis, current infrastructure, parameters evaluation and the way forward to the problems are discussed. Comparative analysis between the existing network infrastructure that is $3 G$ networks and the proffer solution to the existing standard which is $4 G$ network is also conducted. This paper also conducts an analysis on the existing Network providers in the region with their draw backs and the quality of services they provide to the customers within the region. The paper concludes with a future plan of coming up with an analytical solution in order to study the implementation process of a full $4 G$ network in the Northwest region of Nigeria and to use a simulated environment to test the proposed model for viability.
\end{abstract}

\section{KEYWORDS}

Telecommunication, $3 G$ networks, $4 G$ Networks, Northwest Nigeria

\section{INTRODUCTION}

Nigeria which is the most populous country in Africa has the Africa's largest mobile market with almost150 million subscribers[1]. The use of Internet and mobile communication has increased tremendously in Nigeria in recent years[2]. The statistics shows that there are more than 50 million internet users within the country in both rural and urban areas.

The country is in the emerging and developing phase but broadband services are at low level in some regions of the country especially the north western region of the country. But CISCO projected that the broadband services are expected to grow significantly. Though, the growing traffic may have some implications in terms of the capacity requirements for broadband 
infrastructure. Globally, there are about 3 billion internet users with over $65 \%$ of them coming from the developing world and $50 \%$ of these subscriptions are expected to be in the developing world[3].

This paper aimed at investigating the Telecommunication Network infrastructure in Northwestern part of Nigerian to propose some technologies that increase data bandwidth and internet penetration in the region. The services of current network will be compared with the proposed improvement. The region is now facing so many challenges in terms of network infrastructure that include: Minimum network connection that are caused by inadequate number of base stations, inadequate power supply and cost effectiveness. Furthermore, the location of the Internet Service Providers (ISPs) also affects the internet connection.

Currently, the mobile telecommunications service provision in Nigeria is shared among four(4) telecommunication companies namely; MTN, GLO, AIRTEL and ETISALAT. Moreover, apart from making calls, these networks service providers also provide many promising services including; affordable internet services, internet banking, mobile banking and mobile tracking services. Meanwhile, the top two (2) network operators; MTN Nigeria and Airtel Nigeria accounted for 68.0 percent of overall service revenue in 2014-2018[4].

Telecommunication Industries plays an important role in boosting the social and economic infrastructure of Nigeria. And it also promotes and improves the delivery of basic services that enhance the development of the nation. Meanwhile, the North Western region of Nigeria is the most populous region in the country but the network infrastructure is poor compare to the North central region of the country. Therefore, to investigate the Telecommunication Network infrastructure in the Region and to propose some technologies to increase data bandwidth and internet penetration in the region is highly important. The Northwest states include Kano, Kaduna, Jigawa, Katsina, Kebbi and Zamfara.

This paper is organised as follows after introduction, followed by section two which described the current network infrastructure in Northwest Nigeria. Section three of the paper is the analysis of mobile market in northwest that describes how mobile devices are used in the region compare to other form of communications.Advent of smart devices in the region is section four of the paper followed by current and sufficient network infrastructure in the region as section five. Section six of the paper is parametric evaluation of the existing standards based on quality of service in the region. The final section before conclusion is section seven which described the way forward to the existing problems.

\section{NORTH WEST CURRENT NETWORK INFRASTRUCTURE}

As stated earlier in the introduction section, Nigeria remains the most populous country in Africa, with population of over 170 million people. The country is currently the Africa's largest economy but the mobile penetration on a unique subscriber basis is very low (about 30\%) compare to other African countries like South Africa and Egypt with 65\% and 50\% respectively[5].Nevertheless, there exists a significant variation of services by the network service providers within the country. And also differences in network access between northern and southern part of the country always draw the attention of many northerners.

Because the southern part such as Lagos state and those states clustered around the oil-rich Niger Delta, generally always have much higher access than in the north. But there is a clear opportunity to improve the mobile infrastructure to enable network access and provide the basic services needed in the entire northern part. 
This will drive wider socio-economic development not only to the Northern part, but the country at large through innovative presentations and the use of mobile broadband. However, the North Western region is among the regions that are left behind in terms of network infrastructure despite their population. In a bid to enhance the services of the networks, the telecommunication companies upgrade their service from generation to generation. The $\mathrm{G}$ mobile generations are $1 \mathrm{G}$, $2 \mathrm{G}, 3 \mathrm{G}$ and $4 \mathrm{G}$ representing the first, second, third and fourth generations respectively. Although $5 \mathrm{G}$ network is already in existence in some developed countries like United Kingdom, United State and the like. The first 3G services was launched by MTN in 2007 but four (4) years later Globacom then launched the $4 \mathrm{G}$ service specifically for corporate backhaul users[5]. The quality of services improves as the generation increases. The evolution of the mobile technologies from $1 \mathrm{G}$ to $4 \mathrm{G}$ LTE delivers more capacity for faster and better internet connectivity and mobile broadband experiences. Based on the current study, it is revealed that up till now $4 \mathrm{G}$ network has not been utilise with maximum utilisation in the region compare to other part of the country and the entire globe. Therefore, it is expected that the existing infrastructure require a thorough upgrade in order to meet up with global standard.

\section{NORThWeSt Mobile MARKet ANALysis}

The country has the largest mobile market in Africa that attracted different range of investors. The top three (3) operators - MTN, Airtel and Globacom topped the market with about $85 \%$ of the market. The table below shows some elements in the Nigerian mobile market for six (6) years from $(2013-2018)$.

Table 1: Market analysis in 6 years from GSMA intelligence

\begin{tabular}{|l|l|l|l|l|l|l|c|}
\hline S/N & Element & $\mathbf{2 0 1 3}$ & $\mathbf{2 0 1 4}$ & $\mathbf{2 0 1 5}$ & $\mathbf{2 0 1 6}$ & $\mathbf{2 0 1 7}$ & $\mathbf{2 0 1 8}$ \\
\hline 1. & Connection (M) & 87 & 95 & 113 & 127 & 145 & 152 \\
\hline 2. & \% Active & $98 \%$ & $98 \%$ & $98 \%$ & $97 \%$ & $97 \%$ & $96 \%$ \\
\hline 3. & Penetration (M) & 36.5 & 39.2 & 45.5 & 51.1 & 58.0 & 62.0 \\
\hline 4. & Penetration per Unique subscriber & $23 \%$ & $24 \%$ & $27 \%$ & $29 \%$ & $32 \%$ & $34 \%$ \\
\hline 5. & Connection growth (Annual) & $19 \%$ & $9 \%$ & $19 \%$ & $19 \%$ & $12 \%$ & $14 \%$ \\
\hline
\end{tabular}

Moreover, the table below shows the breakdown of the Nigeria Telecommunication networks market shares from 2016 to 2018.

Table 2: Mobile Market share in Nigeria

\begin{tabular}{|l|l|l|l|l|}
\hline \multirow{2}{*}{ S/N } & \multirow{2}{*}{ Network } & \multicolumn{3}{|c|}{ Shares per year } \\
\cline { 3 - 5 } & & $\mathbf{2 0 1 6}(\%)$ & $\mathbf{2 0 1 7}$ (Millions) & $\mathbf{2 0 1 8}$ (Millions) \\
\hline 1. & MTN & $42.4 \%$ & $57,183,745$ & 60.7 \\
\hline 2. & GLO & $21.9 \%$ & $26,194,336$ & 37.3 \\
\hline 3. & Airtel & $19.46 \%$ & $24,490,650$ & 23.58 \\
\hline 4. & Etisalat & $12.83 \%$ & $18,119,397$ & 22.3 \\
\hline 5. & Others & $3.9 \%$ & 256,124 & 0.28 \\
\hline
\end{tabular}

The bar chart below represent the mobile market shares of the four (4) major telecommunication networks in Nigeria in 2018. 


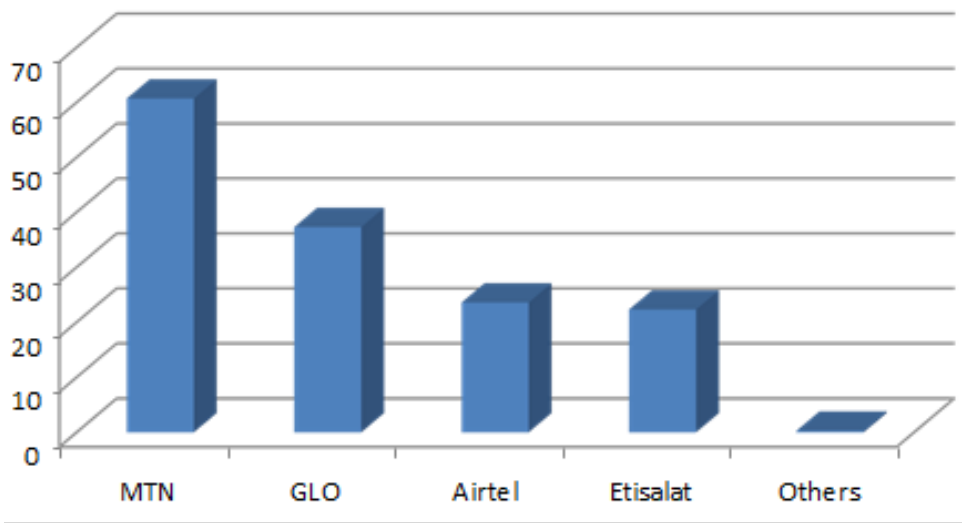

Figure 1: Bar chart showing the market share of the telecommunication networks in 2018

Moreover, [6]investigated the effects of Information and Communication Technology (ICT) to poverty in Nigeria. The paper concluded that poor quality of service, lack of physical and transmission infrastructure and inadequate power supply are the main causes in the North Western region of the country and the country at large. However, [5] expressed that gap exist between people that have access to modern information and communications technology through internet connection and those that have restricted access or no access completely. He further revealed that the digital divide plays a vital role in the country's GDP because by having access to internet one has access to information and having information will help in decision making analysis. Therefore, to improve to the network infrastructure to get high-speed network that is always on and fast is of great importance to the country. And to this, the use of Broadband is highly recommended.

Meanwhile, according to[7], 10\% increase in broadband penetration yields an additional $1.38 \%$ increase in GDP growth for low to middle income countries thereby increasing economic benefits of investing in broadband infrastructure. The author finalized that the Nigerian Communication Commission recognized the low internet penetration and suggested to increase the penetration level from $6 \%$ to $30 \%$ by 2019.

The Nigerian Internet users with growth in percentage and country's population with penetration rate are given in the table 3.

Table 3: Nigeria internet growth between 2014 and 2018

\begin{tabular}{|l|l|l|l|l|l|}
\hline S/N & Year & $\begin{array}{l}\text { Internet } \\
\text { users }\end{array}$ & $\begin{array}{l}\text { User's } \\
\text { growth }\end{array}$ & $\begin{array}{l}\text { Country's } \\
\text { population } \\
\text { (millions) }\end{array}$ & $\begin{array}{l}\text { Internet } \\
\text { penetration (\%) }\end{array}$ \\
\hline 1. & 2014 & $67,101,452$ & $16 \%$ & 178.5 & $37.595 \%$ \\
\hline 2. & 2015 & $57,735,862$ & $4 \%$ & 173.6 & $33.26 \%$ \\
\hline 3. & 2016 & $55,586,299$ & $19 \%$ & 168.8 & $32.88 \%$ \\
\hline 4. & 2017 & $46,680,049$ & $22 \%$ & 164.2 & $28.43 \%$ \\
\hline 5. & 2018 & $38,329,687$ & $23 \%$ & 159.7 & $24.00 \%$ \\
\hline
\end{tabular}


International Journal of Computer Science \& Engineering Survey (IJCSES) Vol.10, No.1, February 2019

\section{Advent Of Smart Devices In The North West Of Nigeria}

An average Nigerian residing in the part of the regions can now afford a smart phone that he/she uses not only to make calls, but to browse especially to read newspapers and watch /stream some videos. And to do these, he needs at least a $3 \mathrm{G}$ connection. But the telecommunication companies failed to make the $3 \mathrm{G}$ connection accessible in some regions of the country. Thus, the $3 \mathrm{G}$ and $4 \mathrm{G}$ are only available in some selected cities of the country where the northwest states are one of the beneficiaries. Whereas, people do require it in all the regions of the country to enable them browse, read news or report any incident that may happen to them. But the absence of the internet connection in some regions of the country, this may lead to companies losing benefit attach to that. The generations are explained in table 4 .

Table 4: Evolution Cellular network Technologies

\begin{tabular}{|l|l|l|}
\hline S/N & Technology & Details \\
\hline 1. & $\begin{array}{l}\text { 1G (first generation), } \\
\text { AMPS, NMT, TACS }\end{array}$ & $\begin{array}{l}\text { This technology was analogue and therefore established unified mobile } \\
\text { connectivity with analogue transmissions that are inefficient and limited } \\
\text { capacity \& scalability. }\end{array}$ \\
\hline 2. & $\begin{array}{l}\text { 2G Decond } \\
\text { Generation)- } \\
\text { AMPS, GSM/GPRS }\end{array}$ & $\begin{array}{l}\text { In this generation, the voice capacity have been increased by digital } \\
\text { wireless technologies delivering better mobile services through digital } \\
\text { transmissions that enabled compressed voice and multiple users per } \\
\text { channel }\end{array}$ \\
\hline 3 & $\begin{array}{l}\text { 3G (third generation)- } \\
\text { WCDMA/HSPA+, } \\
\text { TD-SCDMA }\end{array}$ & $\begin{array}{l}\text { This is the optimization of the 2G where the mobile Broadband Data had } \\
\text { been optimized. The 3G optimizes mobile services enabling a mobile } \\
\text { broadband service that evolves faster and better connectivity than the 2G. }\end{array}$ \\
\hline 4 & $\begin{array}{l}\text { Generation)- LTE, } \\
\text { LTE Advanced }\end{array}$ & $\begin{array}{l}\text { The 4G LTE is very flexible and supports wider channels with more data } \\
\text { capacity that connects more users. The technology delivers more capacity } \\
\text { for faster and better mobile broadband services, and is also expanding in } \\
\text { to new frontiers. }\end{array}$ \\
\hline
\end{tabular}

In a bid to investigate the performance of telecommunication networks in Nigeria,[8] reviewed the standard performance metrics as indices for performance measurement where he expressed that it is possible to assess the performance of the mobile market in terms of operators' market share and the capacity of the market to generate employment. He further reported that the Internet penetration is at its low level in the Northern part of the country with an overall level of $2 \%$, where most of the internet users are found in Lagos state which is in the Southern part of the country. However, the second largest number of subscribers can be found in Kano state which is in one of our area of study.

\section{Current And Sufficient Network Infrastructure In North WEST NIGERIA}

In various parts of the world, $3 \mathrm{G}$ networks uses different radio frequencies with the $2 \mathrm{G}$ and this characteristics leads to building of entirely new networks and license with entirely different frequencies. Therefore, the number of spectrum allocation decisions, its standardization, availability and the technology innovations, component development and signal Processing must be available for the $3 \mathrm{G}$ network to be improved[9]. As stated earlier, radio frequencies use in $3 \mathrm{G}$ networks is different with $2 \mathrm{G}$ frequencies, likewise the security features is also different. 
There exist different of features that attached to $3 \mathrm{G}$ architecture and these include:

1. Network Access Security: This part enables the subscribers to securely connect to the services provided by the $3 \mathrm{G}$ network. It provides the confidentiality of identity of the subscribers.

2. Network Domain Security: This feature is responsible for the exchange of data and protects the network from wired attacks

3. User Domain Security: This feature allows the user to securely connect to mobile stations.

4. Application Security: This enables applications in the user domain and the provider domain to securely exchange messages.

5. Visibility and Configurability of Security: This feature allows users to enquire the kind of security features that are available on the system

However, [10]highlighted that the $3 \mathrm{G}$ allows for high-speed transfer of both voice and data. This improve the availability of more convincing multimedia content coupled with high capabilities of devices performance are likely to increase. Moreover, $3 \mathrm{G}$ provides a wide variety of audio, video and data services.

However, [11] also expressed that different mobile communication technologies exist including WiMAX, Wibro, EDGE, GPRS and many others. The mobile communication technologies are based on different transmission protocol and security standards. He discussed in detail about 3G (Third Generation) technologies and concluded that $3 \mathrm{G}$ is the gateway for improved bandwidth, multiple mobile applications and clarity of digital signals. Moreover, the 3G mobile technologies offers more advanced services to mobile users.

\section{Parameter Evaluation Based On Service Delivery}

To evaluate the performance of the existing infrastructure, some parameters has to be consider that helps many multimedia services like streaming video using the CBR application, the VOIP and FTP to function. Since 3G networks support multimedia services, the network performance is usually tested by some of the matrices that are listed below:

\subsection{DELAY}

Delay of a network is one of the important network designs that determine how long it takes for a bit of data to move across the network from one node to another. The delay can be divided into four (4) kinds, namely; processing delay, queuing delay, transmission delay and propagation delay. The four (4) kinds are represented in the figure 2.

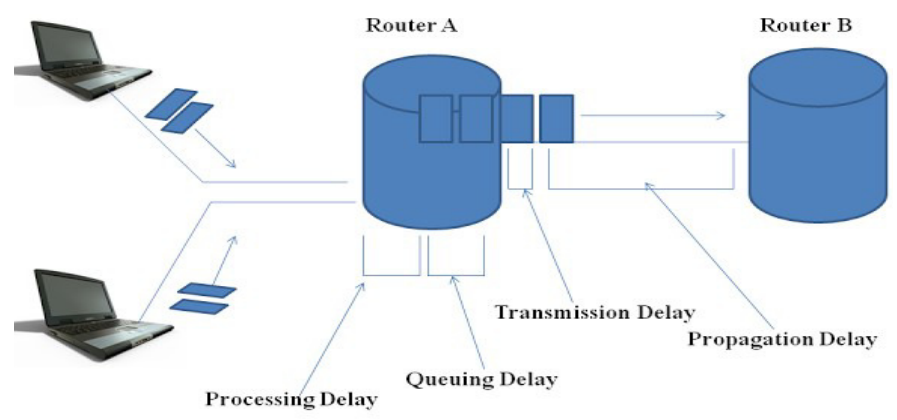

Figure 2: Kinds of delays 
Transmission delay is mathematically given as:

Delay of a packet $=$ time packet received at server - time packet transmitted at client.

Where times are in seconds.

\subsection{PACKet Lost}

Packet loss is defined as the failure of one or more transmitted packets to reach destination within the required time.

\subsection{THROUGHPUT}

This is defined as a measure of how many units of information can be processed by a system in a given period of time. It describes the rates at which the network was able to send the data packets from the source to the destination. This is measured in bit per seconds, bps.

$$
\text { Throughput }=\frac{\text { Total bytes received } * 8}{\text { simulation time-time of first packet received }}
$$

Where time is measured in seconds.

\subsection{JITTER}

Jitter is defined as any deviation in the signal pulse in a high-frequency digital signal. And the deviation can be in terms of amplitude or phase timing. There many causes of the jitter and these include cross communication with other signals and electromagnetic magnetic interference.

$$
\text { Average jitter }=\frac{\text { Total packet jitter for all received packets }}{\text { number of packets received }}
$$

The figure demonstrates jitter on connection.

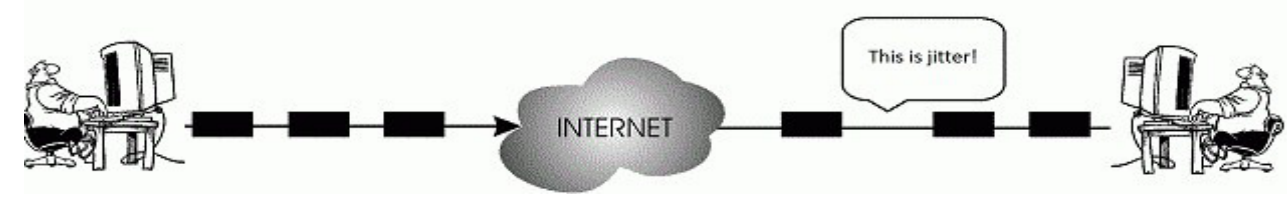

Figure 3: Demonstrating Jitter

\subsection{RELIABILITY:}

This is defined as a characteristic of any computer-related component either software, hardware or a network that always performs according to its specifications. Thus, it is the ability to experience failures of network without impacting customers or operations. Apart from the matrices that exist in $3 \mathrm{G}$ networks, as mention earlier, some of the applications used by this network stated below:

\subsubsection{CBR (Streaming services):}

Constant bit rate is an application for Streaming media either video or audio content sent in a compressed form over the Internet and played immediately and directly rather than being downloaded and saved to the hard drive. 


\subsubsection{FTP (File transfer protocol):}

File transfer protocol is a computer network protocol that is used for transferring computer files between the client and server. This protocol has it standard that support services like emails and heavier messages over a computer network.

\subsubsection{VOIP (Voice over IP):}

Voice over internet protocol is a kind of application that enables subscribers to use the internet as a medium for transmission of telephone calls by sending voice data in packets using IP.
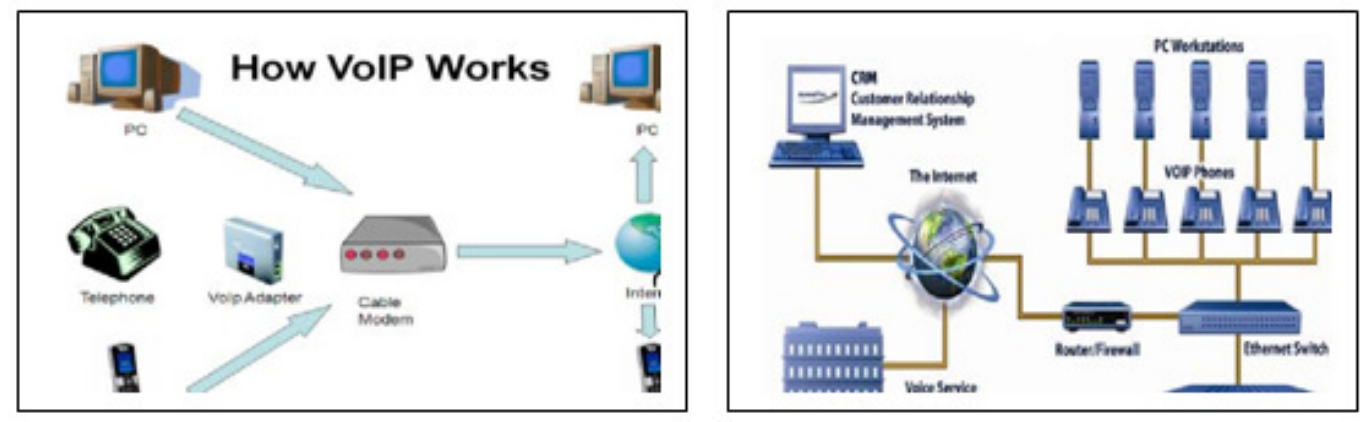

Figure 4: Voice over Internet Protocol (VoIP)[12]

\subsubsection{Network Density}

Network density is defined as the ratio of all tie strength that is actually present to the number of possible ties in a network.

According to[13] highlighted that the development of $3 \mathrm{G}$ service has important economic and social impacts. He further revealed that successful development of $3 \mathrm{G}$ service can help developing countries to close technology gap that exist between them and the developed countries. Meanwhile [14]designed two (2) algorithms for delay to learn offloading of bulky data from $3 \mathrm{G}$ networks. The first algorithm was the "MixZones" which uses ad hoc transfers between users and is assisted by predictions made by the network operator. And the second algorithm was "HotZones" that exploits delay tolerance and tries to download contents when users are close to Wi-Fi access points. They further concluded that the performance evaluation of the two designed algorithms was realistic and also helps community get better idea of the performance of a large scale delay tolerant application in a mobile network.

In relation to current standard, [15]highlighted that; despite the long existence of the telecommunication network in Nigeria, the country still has a low penetration of fiber optic network. Though there exist a lot of fiber optic backbone cables in the country. He further expressed an assessment of the activities of fiber optic operations in terms of coverage, utilization and volume. He also investigated the factors affecting the broadband penetration in Nigeria and solutions were suggested.

However, [1]expressed that Nigeria has a fast growing economy but the majority of the population are lacking internet access and also have income inequality. Meanwhile, there are various factors that cause the above problems and these include; high access rate, high mobile data consumption and nearness to the connections. 
International Journal of Computer Science \& Engineering Survey (IJCSES) Vol.10, No.1, February 2019

\section{SUMMARY OF REVIEW}

It has been observed that Nigeria has the largest mobile market in Africa that attracted different range of investors. But there exists a variation of services by the network service providers in Nigeria. Thus there are differences in network access between northern and southern part of the country. The first 3G services were launched by MTN in 2007 which topped the list in mobile infrastructure in the country followed by Globacom that launched 4G for corporate backhaul users. It is noted from the literatures that increase in broadband penetration leads to increase in GDP of the country. But there are many factors affecting the broadband infrastructure that need to be addressed.

Meanwhile, researchers in various parts of the world used the network simulators and improved the data bandwidth and internet penetration of some areas. They concluded that improving the network infrastructure through the introduction of some technologies such as satellite, microwave link, better backhaul, more base stations and deployment of $4 \mathrm{G}$ networks will increase the number of subscribers and therefore improves the economic level of a country.

After careful review of different literatures in this paper, including problems of the $3 \mathrm{G}$ network in the various regions in the world and the solutions that have been suggested by different authors, it is found worthy to use the $4 \mathrm{G}$ network as a solution to the existing network problem in the North Western part of Nigeria.

\section{WAY FORWARD TO A BETTER INFRASTRUCTURE}

The problem of Network infrastructure in the North Western region of Nigeria may be solved by suggesting a technology that will improve internet penetration and data bandwidth. Different authors in various parts of the World used different technique and improved the data bandwidth and internet penetration of those areas.

Considering issues that has to do with foresight, [16]highlighted that without adequate foresight, some technologies that meant for improvement may end up being destructive. They investigated four potentially troublesome technologies including millimetre wave wireless, the Internet of Things (IoT), Fog Computing, and Software Defined Networking (SDN). They examined cases proposed by academia into the bandwidth requirements for applications, and use this data to forecast future traffic. Moreover, they revealed that Mm-wave carrier frequencies permit higher bandwidth allocations with higher data transfer rates that increases data capacity.

And with the improved bandwidth that connects the base station- to-device, and the backhaul links between base stations provides a greater capacity to transfer high data and accommodate increased data traffic. [17]expressed that mobile operators that are expanding their services into rural and remote areas have a multitude of backhaul technologies. However, choosing proper technology and better location increases and supports the number of subscribers in those areas. Furthermore, he added that the improvement of the network infrastructure will increase the number of subscribers and therefore improves the economic level of a country. He further revealed that with the improvement in the network infrastructure, Indian mobile subscribers have been increased by 114 million in 2008 alone. While China Mobile, which is the world's largest operator, added another 30.8 million subscribers in the first five months of 2009 alone. He concluded that there are several benefits and opportunities for improving the network penetration into rural and remote areas and advantages include: 
Maintaining customer loyalty

Social and economic benefits: Different emerging economies have significantly improved as a result of improving the mobile network infrastructure which increased access to information, encourages education and improved social connections.

New services

On the other hand, [18]expressed that 3G (Digital broadband packet data) existed from 20042005 (though it still exists) with technologies including; CDMA 2000, EVDO and EDGE. He examined that the bandwidth speed of the $3 \mathrm{G}$ is $500-700 \mathrm{Kbps}$ during off peak period and 3.1 Mbps during peak period. They observed that the $3 \mathrm{G}$ has multimedia with very good streaming services and it runs across different devices.

Meanwhile, [19]investigated the Broadband wireless access distributions where they proposed an architectural framework to support the incorporation of Wi-Fi and WiMAX technologies in rural communities in the Southern part of Nigeria. They examined on bridging the gap between the rural and urban areas where they used Jeddo community as a case study. Their researched was on the implementation of wireless broadband access, with WiMAX and Wi-Fi. They further used some cable based and digital Subscriber Line (DSL) technologies can be implemented and might work perfectly.

In addition, Nigeria National Broadband Plan (2013) highlighted that the use of $3 \mathrm{G}$ and $4 \mathrm{G}$ will enhance the economic growth of the country and promotes the government services. The committee also revealed from its report that the services of $4 \mathrm{G}$ are significantly higher than even $3 \mathrm{G}$ talk less of the other lower generations. Table 5 shows the users experience on the $3 \mathrm{G}$ versus the $4 \mathrm{G}$ access technology:

Table 5: User Experience; $3 \mathrm{G}$ vs 4G

\begin{tabular}{|l|l|l|l|}
\hline S/N & Activity & 3G (1.5 - 3Mbps $)$ & 4G (10 - 20Mbps) \\
\hline 1. & HD video screaming & $<5$ minutes buffer & $<30$ seconds \\
\hline 2. & Audio streaming & $<10$ seconds buffer & $<1$ seconds \\
\hline 3. & Watch a Youtube video & $<20$ seconds & $<1$ seconds \\
\hline 4. & Posting a picture to facebook & $<25$ seconds & $<1$ seconds \\
\hline 5. & Downloading A 20MB file & $<3$ minutes & $<25$ seconds \\
\hline
\end{tabular}

With regards to existing infrastructure, [20]studied the $3 \mathrm{G}$ network and investigated the mobile communication systems beyond the third generation (3G). It is expected that subscribers will access unlimited amount of multimedia and voice data with high quality of service (QoS) and greater throughput per subscriber. They proposed fourth generation $(4 \mathrm{G})$ network as a solution to the problems of the $3 \mathrm{G}$. It will improve the capacity of $3 \mathrm{G}$ and offer an entirely packet switched network with data rates expected to range from $100 \mathrm{Mbps}$ to $1 \mathrm{Gbps} .3 \mathrm{G}$ architecture and cellular structure has to be upgraded to meet the target of $4 \mathrm{G}$ systems. Also, [20]highlighted that the main challenge in the development of wireless communication systems is to provide various services across different radio access technologies through a single mobile terminal.

However, [21]used the $4 \mathrm{G}$ network as a solution to existing problems of $3 \mathrm{G}$ network and concluded that the $4 \mathrm{G}$ provide low cost per bit, Voice (VoIP), high speed and capacity. They 
further expressed that $4 \mathrm{G}$ is all about an integrated global network. Currently, several technologies are capable of performing like broadband data access in mobile and supporting voice traffic using voice over IP (VoIP).But what subscribers need is new technologies that will allow merging, bridging and integrating separate systems into an information delivery system.

The figure 5 represents the structure of $4 \mathrm{G}$.

\section{Gobile Communications}

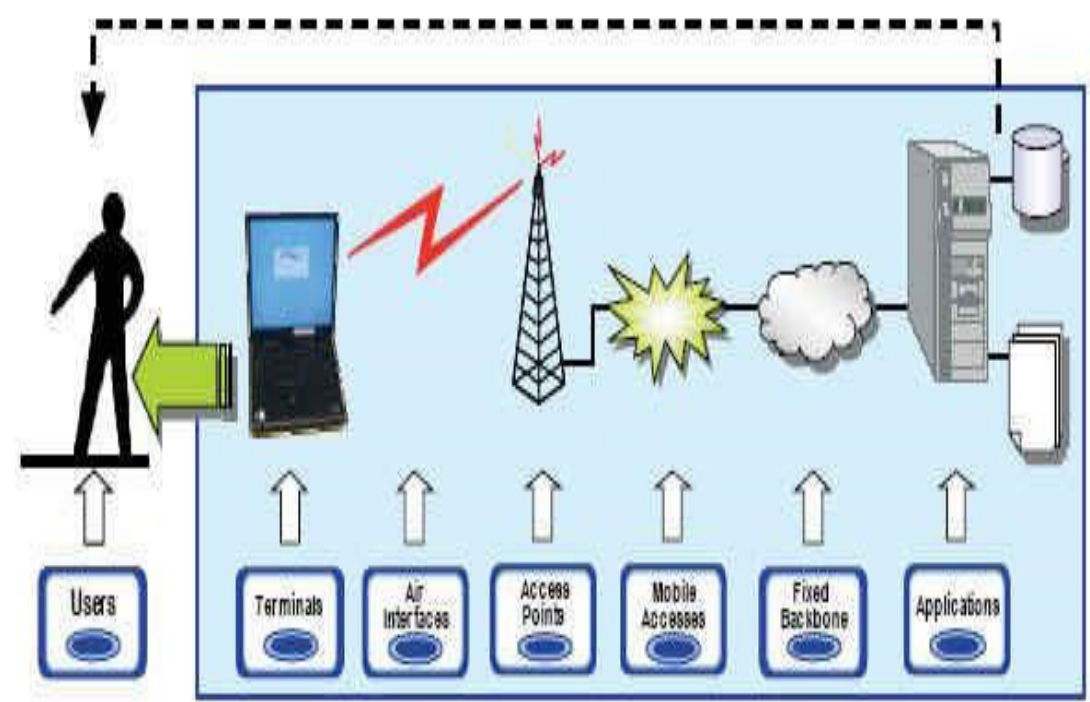

Figure 5: 4G network structure[22]

When considering other standards, [23]revealed that $4 \mathrm{G}$ mobile systems focus on integrating the existing wireless technologies including GSM, wireless LAN and Bluetooth. Unlike 3G.4G system supports standard services, providing stable system performance and quality of service. Mean the 3Gsystems to $4 \mathrm{G}$ faces many challenges. They also discussed these challenges and limitations of the $3 \mathrm{G}$.

The $3 \mathrm{G}$ network has limited coverage: As the data speed increases the coverage area decreases.

$>$ Using WCDMA cells, with the increase in data rate, the speed of user terminals decreases.

$>$ The bandwidth increases exponentially as users increase within a cell. Therefore, having more subscribers requires more base stations to boost the shared bandwidth.

$>$ Impossibility to connect the HSPDA by wireless connection in cellular technology.

Figure 6 shows the $3 \mathrm{G}$ network as the current network and $4 \mathrm{G}$ as a solution to some of the problems of the $3 \mathrm{G}$. 


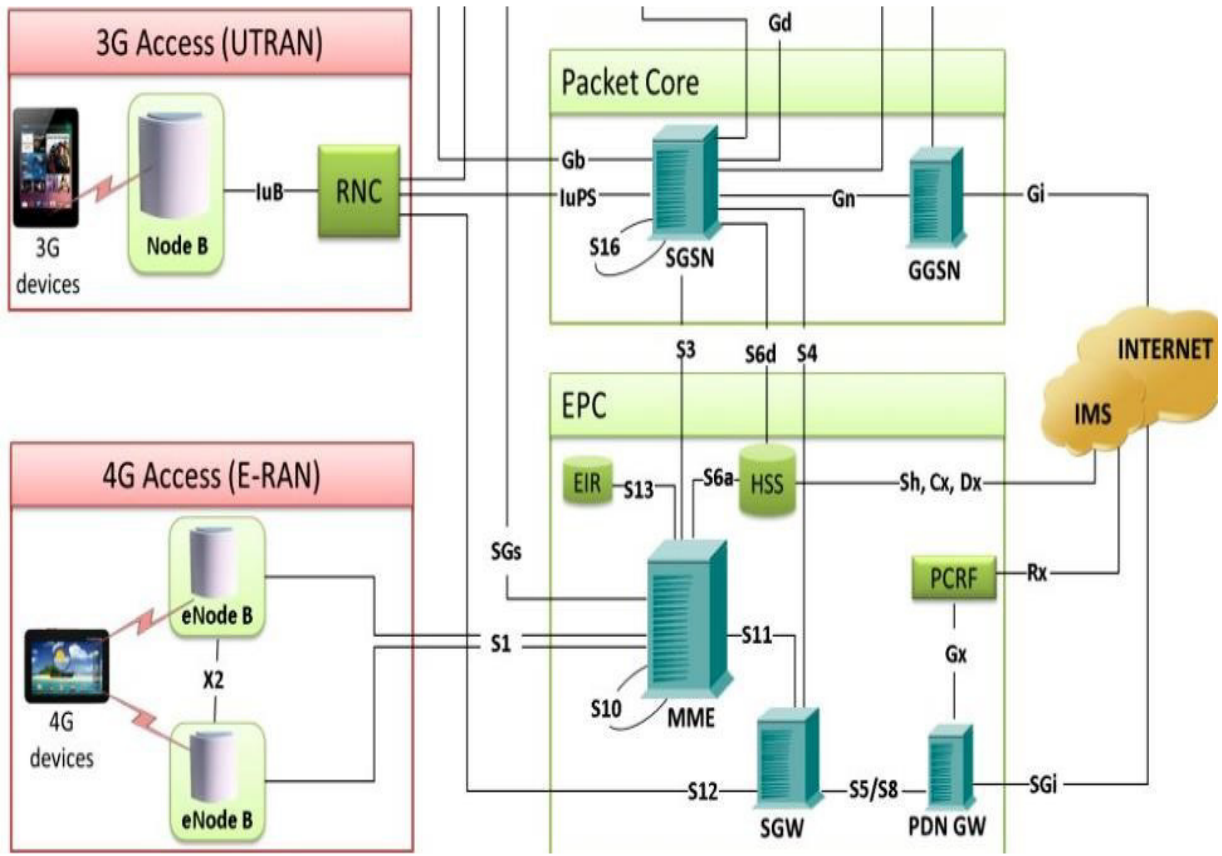

Figure 6: Showing $3 \mathrm{G}$ and $4 \mathrm{G}[24]$

However, [25]examined the visions of $4 \mathrm{G}$ from a technical point of view and they further presented an overall feature of $4 \mathrm{G}$ feature framework based on the kernel concept of integration. The features described are diversity and adaptability. Then, along the entire $4 \mathrm{G}$ domain, each feature in the framework is deeply discussed from a technical standpoint. They concluded that $4 \mathrm{G}$ is served as a solution to problems of $3 \mathrm{G}$ network.

In[26], the paperconcluded that there is a strong need to integrate WLANs with $3 \mathrm{G}$ mobile data networks to develop hybrid mobile data networks that will allow very high data rates in strategic locations. He suggested this need by proposing some architecture that are able to provide interworking between WLAN and the $3 \mathrm{G}$ networks in order to meet the requirements of a common interworking scenarios. The architectures can allow $3 \mathrm{G}$ subscribers to benefit from high-throughput IP connectivity in hotspots.

\section{CONCLUSiON}

This paper reviews and investigates the current status of telecommunication network infrastructures in the Northwest province of Nigeria with the aim of exploring problems and solutions towards optimising the standard. In view of this, the paper highlights the existing service providers in the region with a comprehensive performance with respect to quality of service and other delivery issues. Mobile market analysis is also explored and customer satisfactions in terms using mobile devices and used of different internet service providers. Analysis on the functional network standard which is $3 \mathrm{G}$ network as an out dated infrastructure is also conducted and the future network standard which is pure $4 \mathrm{G}$ network is elaborated. To proof the importance of study, two different scenarios was created after conducting a thorough review on the existing infrastructure that is, apure $3 \mathrm{G}$ network and $4 \mathrm{G}$ network with full physical characteristic of the region and defining a suitable parameters of each scenario in order to validate the research study. The results defined the existing problems and future solutions of the existing network infrastructure in the province. Based on the results obtained, throughput, delay, packet lost, jitter and other conditions are among the factors that were considered in drawing the 
problems and future solutions of the existing network. After these analysis, the paper proffer an extensive way forward towards optimising the existing network infrastructure in the Northwest province in Nigeria through upgrading and implementing full $4 \mathrm{G}$ network in the region. The future research of this study is to come up with an analytical model that will study the implementation of $4 \mathrm{G}$ network in the region and to use a simulated environment in order to test the viability of the model.

\section{REFERENCES}

[1] N. C. Commission, "Subscriber statistics," Retrieved on 2nd February, 2018.

[2] H. Gruber and P. Koutroumpis, "Mobile telecommunications and the impact on economic development," Economic Policy, vol. 26, no. 67, pp. 387-426, 2011.

[3] K. M. Reilly and M. L. Smith, "The emergence of open development in a network society," Open development: Networked innovations in international development, pp. 15-50, 2013.

[4] T. T. Alabar, O. Egena, and R. I. Gbande, "Service quality and customer satisfaction in Nigerian mobile telephony," International Proceedings of Economics Development and Research, vol. 82, p. 108, 2014.

[5] G. Intelligence, "Sub-Saharan Africa Mobile Economy 2013," See http://www. gsmamobileeconomyafrica. com/Sub-Saharan\% 20Africa_ME_Report_English_2013. pdf (last checked 19 September 2014), 2013.

[6] J. Adewoye and T. Akanbi, "Role of Information and Communication Technology Investment on the Profitability of Small Medium Scale Industries-A Case of Sachet Water Companies in Oyo State, Nigeria," Journal of Emerging Trends in Economics and Management Sciences, vol. 3, no. 1, p. 64, 2012.

[7] E. Agwu and A.-L. Carter, "Mobile phone banking in Nigeria: benefits, problems and prospects," 2018.

[8] A. Milek, C. Stork, and A. Gillwald, "Engendering communication: a perspective on ICT access and usage in Africa," info, vol. 13, no. 3, pp. 125-141, 2011.

[9] K. Kumaravel, "Comparative study of 3G and 4G in mobile technology," International Journal of Computer Science Issues (IJCSI), vol. 8, no. 5, p. 256, 2011.

[10] K. Kumar, J. Liu, Y.-H. Lu, and B. Bhargava, "A survey of computation offloading for mobile systems," Mobile Networks and Applications, vol. 18, no. 1, pp. 129-140, 2013.

[11] A. K. Mogal, "Wireless mobile communication-a study of 3G technology," International Journal of Advanced Networking and Applications, vol. 3, no. 5, p. 1, 2012.

[12] P. Gigis, V. Kotronis, E. Aben, S. D. Strowes, and X. Dimitropoulos, "Characterizing User-to-User Connectivity with RIPE Atlas," in Proceedings of the Applied Networking Research Workshop, 2017, pp. 4-6: ACM.

[13] J.-Y. Le Boudec and P. Thiran, Network calculus: a theory of deterministic queuing systems for the internet. Springer Science \& Business Media, 2001.

[14] B. Palanisamy and L. Liu, "Attack-resilient mix-zones over road networks: architecture and algorithms," IEEE Transactions on Mobile Computing, vol. 14, no. 3, pp. 495-508, 2015.

[15] D. F. Mojisola and K. Gbolahan, "Participatory Analysis of Cellular Network Quality of Service," International Journal of Computing \& ICT Research, vol. 9, no. 1, 2015.

[16] R. Brenner et al., "Development of Wireless Techniques in Data and Power Transmission-Application for Particle Physics Detectors," arXiv preprint arXiv:1511.05807, 2015.

[17] M. Poblet, "Affordable telecommunications," Australian Journal of Telecommunications and the Digital Economy, vol. 1, no. 1, 2013. 
International Journal of Computer Science \& Engineering Survey (IJCSES) Vol.10, No.1, February 2019

[18] K.-D. Chang, C.-Y. Chang, H.-M. Liao, J.-L. Chen, and H.-C. Chao, "A Framework for IoT objects management based on future internet IoT-IMS communication platform," in Innovative Mobile and Internet Services in Ubiquitous Computing (IMIS), 2013 Seventh International Conference on, 2013, pp. 558-562: IEEE.

[19] F. Ibikunle, O. Jakpa, and D. Ike, "Broadband Wireless Access Deployment Approach to Rural Communities," Journal of Computer Networks, vol. 1, no. 3, pp. 38-45, 2013.

[20] W.-H. Sheen, S.-J. Lin, and C.-C. Huang, "Downlink optimization and performance of relay-assisted cellular networks in multicell environments," IEEE Transactions on Vehicular Technology, vol. 59, no. 5, pp. 2529-2542, 2010.

[21] K. Santhi and G. S. Kumaran, "WIMAX WITH WI-FI: OPENING NEW FRONTIERS IN EDUCATION."

[22] J. Lambo, "Telecommunications-Nigeria," 2013.

[23] S.-j. Kim, H. Lee, and M. Lee, "A Study of 4G Network for Security System," The International Journal of Advanced Culture Technology, vol. 3, no. 2, pp. 77-86, 2015.

[24] A. Rusan and R. Vasiu, "Emulation of backhaul packet loss on the LTE S1-U interface and impact on end user throughput," in Intelligent Computer Communication and Processing (ICCP), 2015 IEEE International Conference on, 2015, pp. 529-536: IEEE.

[25] X. Zhang et al., "DSPP mutation in dentinogenesis imperfecta Shields type II," Nature genetics, vol. 27, no. 2, p. 151, 2001.

[26] A. K. Salkintzis, "Wireless IP with GPRS: Fundamental operational aspects," in 4th Int. Symp. Wireless Personal Multimedia Communications, 2001, pp. 7-15. 